\title{
Safety and efficacy of cardiopoietic stem cells in the treatment of post-infarction left-ventricular dysfunction - from cardio- protection to functional repair in a translational pig infarction model
}

Maximilian Y. Emmert, MD, $\mathrm{PhD}^{1,2,3,4}$, Petra Wolint ${ }^{2}$, Andras Jakab, MD, $\mathrm{PhD}^{5}$, Sean P. Sheehy, $\mathrm{PhD}^{4}$, Francesco S. Pasqualini, $\mathrm{PhD}^{3,4}$, Thi Dan Linh Nguyen, $\mathrm{MD}^{6}$, Monika Hilbe, $\mathrm{DVM}^{7}$, Burkhardt Seifert, $\mathrm{PhD}^{8}$, Benedikt Weber, MD, PhD ${ }^{1,4}$, Chad E. Brokopp, PhD ${ }^{1}$, Dominika Macejovska, $\mathrm{MS}^{9}$, Etem Caliskan, $\mathrm{MD}^{2}$, Arnold von Eckardstein, MD ${ }^{10}$, Ruth Schwartlander, $\mathrm{PhD}^{11}$, Viola Vogel, $\mathrm{PhD}^{11}$, Volkmar Falk, $\mathrm{MD}^{12}$, Kevin Kit Parker, $\mathrm{PhD}^{4}$, Mariann Gyöngyösi, MD ${ }^{9}$, Simon P. Hoerstrup, MD, PhD $^{1,2,3,4 *}$

${ }^{1}$ Institute for Regenerative Medicine (IREM), University of Zurich, Zurich, Switzerland

${ }^{2}$ Clinic for Cardiac Surgery, University Hospital of Zurich, Zurich, Switzerland

${ }^{3}$ Wyss Translational Center Zurich, ETH and University of Zurich, , Zurich, Switzerland

${ }^{4}$ Disease Biophysics Group, Wyss Institute for Biologically Inspired Engineering, School of Engineering and Applied Sciences, Harvard University, Cambridge, USA

${ }^{5}$ Department of Biomedical Imaging and Image-guided Therapy, Medical University of Vienna, Vienna, Austria

${ }^{6}$ Institute of Diagnostic Radiology, University Hospital Zurich, Zurich, Switzerland

${ }^{7}$ Institute of Veterinary Pathology, Vetsuisse Faculty, University of Zurich, Zurich, Switzerland

${ }^{8}$ Department of Biostatistics; Epidemiology, Biostatistics and Prevention Institute, University of Zurich, Zurich, Switzerland

${ }^{9}$ Department of Cardiology, Medical University of Vienna, Vienna, Austria ${ }^{10}$ Institute for Clinical Chemistry, University Hospital Zurich, Zurich, Switzerland

${ }^{11}$ Department of Health Science and Technology, Laboratory of Applied Mechanobiology, ETH Zurich, Zurich, Switzerland

${ }^{12}$ Clinic for Cardiac Surgery, German Heart Center Berlin, Berlin, Germany

\section{Corresponding author:}

Simon P. Hoerstrup, MD, PhD

Institute for Regenerative Medicine

University of Zurich

Moussonstrasse 13, $\mathrm{CH}-8091$ Zurich, Switzerland

Tel.: +41-(0)44-634-5610 Fax: +41-(0)44-634-5608

Email: simon philipp.hoerstrup@usz.ch

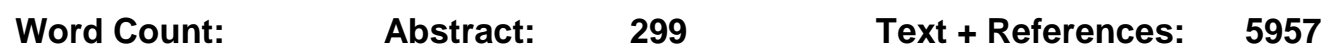

Figures: 8

Suppl. Files: 1

Suppl. Figures: 8

Suppl. Tables: 15

Key Words: cardiopoietic stem cell therapy, mesenchymal stem cells, lineage-specification, guided cardiopoiesis, post-infarction left-ventricular dysfunction, left-ventricular remodelling, chronic heart-failure 


\section{Abstract}

To date, clinical success of cardiac cell-therapies remains limited. To enhance the cardioreparative properties of stem cells, the concept of lineage-specification through cardiopoietic-guidance has been recently suggested. However, so far, only results from murine studies and from a clinical pilot-trial in chronic heart-failure (CHF) are available, while systematic evidence of its therapeutic-efficacy is still lacking. Importantly, also no data from large animals or for other indications are available. Therefore, we here investigate the therapeutic-efficacy of human cardiopoietic stem cells in the treatment of post-infarction LVdysfunction using a translational pig-model. Using growth-factor priming, lineagespecification of human bone-marrow derived MSCs was achieved to generate cardiopoietic stem cells. Thereafter, pigs with post-infarction LV-dysfunction (sub-acute phase;1-month) were randomized to either receive transcatheter 3D-NOGA electromechanical-mapping guided intramyocardial transplantation of cardiopoietic cells or saline (control). After 30days, cardiac MRI (cMRI) was performed for functional evaluation and in-vivo cell-tracking. This approach was coupled with a comprehensive post-mortem cell-fate and mode-of-repair analysis. Cardiopoietic cell therapy was safe and ejection-fraction was significantly higher when compared to controls $(p=0.012)$. It further prevented maladaptive LV-remodeling and revealed a significantly lower relative and total infarct-size $(p=0.043$ and $p=0.012)$. As in-vivo tracking and post-mortem analysis displayed only limited intramyocardial cardiopoietic cellintegration, the significant induction of neo-angiogenesis ( 40\% higher; $p=0.003)$ and recruitment of endogenous progenitors $(\sim 2.5 x$ higher; $p=0.008)$ to the infarct border-zone appeared to be the major modes-of-repair. This is the first report using a pre-clinical large animal-model to demonstrate the safety and efficacy of cardiopoietic stem cells for the treatment of post-infarction LV-dysfunction to prevent negative LV-remodelling and subsequent CHF. It further provides insight into post-delivery cardiopoietic cell-fate and suggests the mechanisms of cardiopoietic cell-induced cardiac-repair. The adoption of GMP/GLP-compliant methodologies may accelerate the translation into a phase-I clinical-trial in patients with post-ischemic LV-dysfunction broadening the current indication of this interesting cell-type. 


\section{Abbreviations}

MSCs Mesenchymal stem cells

LV Left-ventricle

MI Myocardial-infarction

CHF Chronic Heart-failure

cMRI Cardiac magnetic-resonance imaging

GMP Good Manufacturing Practice

SOP Standard operating procedures

EF Ejection-fraction

CO Cardiac-output

SV Stroke-volume

EDV End-diastolic volume

ESV End-systolic volume

LVMV Left-ventricular mass volume

MPIO Micron-sized iron-oxide particles

vWF von Willebrand-Factor

NOGA 3D electromechanical mapping guided intramyocardial stem cell delivery system 


\section{Introduction}

Stem cell therapy has been repeatedly proposed as a promising strategy to treat myocardialinfarction (MI) and chronic heart-failure (CHF) [1-3]. Based on numerous promising preclinical studies [4-6], the feasibility and safety of cell-therapies were confirmed in clinical pilot-trials [7-11]. However, with regards to efficacy, the currently available data display only heterogeneous outcomes and limited improvement of cardiac-performance [1, 2, 12, 13]. Importantly, most of these initial trials have employed unselected, first-generation cell-types with limited cardioreparative properties. An additional element that further complicates the assessment of cell-therapies is the heterogeneity in the design of preclinical studies (i.e. methodologies and endpoints) and inconsistencies between pre-clinical and clinical study approaches [14]. Moreover, randomization, blinding, and GMP-/GLP-compliant methodologies are infrequently used. Finally, the selection of a single primary outcome, while important for statistical considerations, limits the appreciation of the multi-faceted nature of heart disease and its therapy $[14,15]$. Therefore, there is a need for a paradigm shift to develop standardized next-generation cell-therapy protocols for targeted heart-repair [1].

As one example, to enhance the therapeutic-efficacy of current cell-therapy strategies, the concept of cell lineage-specification through cardiopoietic-guidance has been reported [1618]. Following small-animal studies [19], mesenchymal stem cells primed for cardiopoiesis (cardiopoietic stem cells) were shown to be safe in humans [7] (C-CURE trial; NCT00810238) and are currently being tested for efficacy in the larger CHART-1 trial (NCT01768702) enrolling 240 patients with CHF. However, while all previous applications of this strategy have focused primarily on CHF, little is known about its regenerative potential in the treatment of LV-dysfunction in the sub-acute phase after MI to prevent negative LV remodeling and subsequent development of CHF. Moreover, to date, no preclinical largeanimal data of this next-generation cell-therapy concept do exist.

Therefore, in this translational study, we investigated the safety and efficacy of cardiopoietic stem cells in the treatment of post-MI LV-dysfunction. We hypothesized that if administered in the sub-acute phase after $\mathrm{MI}$, cardiopoietic cell therapy may preserve cardiac- 
performance, and thus prevent the potential progression from post-MI LV-dysfunction to negative LV remodeling and subsequent CHF. Importantly, we employed a fully translational pipeline including i) the choice of a relevant large-animal model; ii) GMP-compliant cellhandling; iii) transcatheter 3D-NOGA-assisted transcatheter intramyocardial delivery; iv) clinical-grade randomization, blinding, and endpoint-assessments; v) and state-of-the-art cardiac MRI-based cell-tracking methods linked to a comprehensive post-mortem cardiopoietic cell-fate evaluation.

\section{Materials \& Methods}

For detailed and extended methods please see supplementary file.

\section{Production of GMP-grade human cardiopoietic stem cells}

Production of human cardiopoietic stem cells was performed as previously described [7, 19] using Good Manufacturing Practice (GMP) protocols and standard-operation procedures (SOPs). After written informed consent and ethics approval bone marrow was aspirated from hip of six chronic heart failure patients aged from 36-72 years to produce the cells (see supplementary file for patient characteristics).

\section{Quality-control, release-criteria, angiogenic potential and cell-labelling}

A quality-control was carried out under SOPs to ensure purity, identity and homogeneity and sterility. To test the angiogenic potential of cardiopoietic stem cells CellPlayer ${ }^{\mathrm{TM}}$ Angiogenesis 96-well PrimeKit (Essen Bioscience Ltd) were used to monitor the angiogenic potential of cardiopoietic stem cells on in-vitro endothelial tube-formation using conditioned medium. Next, for in-vivo and post-mortem cell tracking purpose, cardiopoietic stem cells for four animals $(n=4)$ were labeled with super-paramagnetic microspheres, co-labeled with Dragongreen fluorochromes (MPIOs; Bangs Laboratories; USA) allowing for additional post- 
mortem analysis (i.e. flow-cytometry and immunohistochemistry). In addition, cells underwent labeling with CellTracker CM-Dil (Invitrogen; Switzerland).

\section{Translational post-infarction LV dysfunction pig model}

Twenty-two adult landrace pigs underwent induction of $\mathrm{Ml}$ at day0 (two pigs died periprocedural) using a standardized "closed-chest occlusion-reperfusion protocol" as previously described [20-22]. At day3 post-MI all surviving animals $(n=20)$ underwent baseline cardiac MRI (cMRI) for functional-analysis and late-enhancement assessment. One month later (day30; sub-acute phase) all animals $(n=20)$ underwent control-angiography to evaluate LAD-patency and left-ventricular (LV) hemodynamic-parameters. Thereafter, animals were randomized and either received 3D-NOGA, electromechanical-mapping guided intramyocardial transplantation of $5 \times 10^{7}$ human cardiopoietic stem cells with a total of 8-12 injections (300ul / per injection; Group A; $n=10$ ) or the same amount of saline (control; Group B; $n=10$ ) All animals underwent a 30-day follow-up (day60) with cMRI, LV-angiography and 3D-NOGA mapping prior to post-mortem analysis (Fig.1, Study flow-chart). All procedures were approved by an Institutional Ethics Committee (University of Vienna) and in compliance with the ARRIVE guidelines.

\section{Randomization and blinding}

Animals were randomized at day30 before treatment and were blinded to the operators. Cardiac MRI data-analysis was performed with the treatment-arms completely unknown to the investigator. NOGA 3D mapping guided intramyocardial transplantation

To deliver into the infarction border-zone of the animals the NOGA 3D electromechanicalmapping guided transcatheter-system was used as previously described [20, 22, 23]. 


\section{Immunosuppression}

Adapted from previous protocols [20, 24] an immunosuppression-regime with Cyclosporine A (Novartis Pharmaceuticals, New Jersey, USA) was administered starting 3days before cell/saline injection in all animals with a loading-dose of $10 \mathrm{mg} / \mathrm{kg}$ daily which was then continued with a dose of $5 \mathrm{mg} / \mathrm{kg}$ daily until the study-end.

\section{Cardiac MRI (cMRI)}

Cardiac MRI (cMRI) was performed to evaluate functional and structural/infarct parameters at day3 post myocardial-infarction (baseline) and at day60 (30days post-transplantation). In four animals $(n=4)$ which received $\mathrm{MPIO}^{+} / \mathrm{CM}$-Dil ${ }^{+}$cardiopoietic stem cells cell-tracking analysis was performed. Two animals $(n=2)$ underwent additional imaging-sessions at the same day (12hours) and day8 post-injection for further longitudinal-analysis.

\section{Gross-examination and histopathological-analysis}

The hearts and tissue-samples from the lungs, liver, spleen, kidneys and bone-marrow were explanted for comprehensive post-mortem analysis to characterize the lesion-morphology (necrosis, fibrosis), the degree of inflammation and immune-response.

\section{Assessment of cardiopoietic cell-fate}

To assess intramyocardial integration and cardiopoietic cell fate, a multimodal post-mortem evaluation-strategy was performed (animals treated with $\mathrm{MPIO}^{+} / \mathrm{CM}$-Dil ${ }^{+}$cardiopoietic cells; $\mathrm{n}=4$ ) and linked to the MRI-guided MPIO-enabled in-vivo analysis (please see supplementary results for further details).

\section{Flow-cytometry}

Defined tissue-samples of approximately $20 \times 20 \mathrm{~mm}$ from the area of injection were processed for flow-cytometry. Additionally, samples from bone-marrow, kidneys, liver, lung, and spleen were processed. 
PCR-analysis

Qualitative and quantitative PCR of representative tissue-samples were performed either targeting human-specific $\beta 2$-microglobulin or Alu-sequence using standard techniques.

\section{Immunohistochemistry}

Immunohistochemistry of paraffin-embedded cardiac tissue-sections was performed in the following manner: fluorescence-imaging was performed detecting the injected cells by targeting the fluorochrome-labelled part of the MPIOs and counterstained with DAPI (Invitrogen/Switzerland). To assess the intramyocardial integration of human cardiopoietic cells, analysis for human-specific MHC-1 (1:500; Epitomics; USA). To verify the mesenchymal-origin of the detected cells a CD105 (1:100; Dako; Switzerland) staining was performed. To determine a potential further differentiation into a cardiac cell-like phenotype, an $\alpha$-actinin (1:500; Sigma Aldrich/Switzerland) staining was done.

\section{Blood-analysis}

All animals underwent blood chemistry analysis including Troponin-T, CK, AST, myoglobin and LDH and blood-gas analysis at baseline before $\mathrm{MI}$, post MI, day3 post MI, day30 before and after intramyocardial cell-delivery and at day60 (follow-up).

\section{Assessment of angiogenesis and endogenous stem-cell attraction}

Neo-angiogenic effects and endogenous stem cell attraction were assessed by staining for CD31 (1:200, Dako, Switzerland; Leica BondMax; Detection kit: HRP, Leica Microsystems Newcastle), von Willebrand Factor (vWF) (1:100, Dako, Switzerland; DAKO Autostainer;

Detection kit: DAKO REAL ${ }^{\mathrm{TM}}$ ) and C-Kit (1:400, Dako, Switzerland; Discovery Ventana XT; Detection kit: OMNIMAP) was performed tissue-sections from the infarct-zone (IZ), the infarct border-zone (BZ) and the healthy zone (HZ). 
Development of an outcome-index to quantify the therapeutic-effect of cardiopoietic stem cell therapy

A fundamental challenge in assessing the safety and efficacy of cell-based therapies is defining aggregated metrics that provide a quantitative and standardized measure of the multi-modal therapeutic-outcome. To address this, we developed an outcome-score,

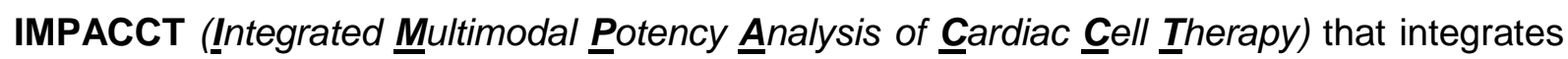
24 experimentally-measured parameters representing five categories of measurements for: cardiac-performance, infarction, structural changes, safety and mode-of-repair (please see supplementary results for further details).

\section{Statistical Analysis}

Statistical analyses were performed using IBM SPSS Statistics, (v22; IBM Corp., Armonk/USA). Quantitative data are presented as mean \pm SEM and significance was considered for $\mathrm{p}<0.05$.

\section{Results}

\section{Generation and transplantation of GMP-grade human cardiopoietic stem cells}

The manufacturing of cardiopoietic stem cells consisted of cell-isolation, expansion, lineagespecification, quality-control (see supplementary file for details) and labelling (Fig.S1). All steps were successfully completed in 4-6weeks according to pre-defined SOPs and Good Manufacturing Practice (GMP).

After the successful induction of the cardiopoietic program (Fig.S2A-C), homogeneity was ensured by the expression of the predefined surface-marker profile comprising of positivity for CD90 and CD105 and negativity of CD34 and CD45 (Fig.S2D). Next, angiogenic-capacity was demonstrated by using an in-vitro endothelial tube-formation assay. Conditioned media from exemplary cardiopoietic cell batches displayed a high and homogenous angiogenic capacity ranging from $40.5 \%-66.9 \%$ relatively to VEGF (control agent) (Fig.S2E-G). Finally, 
after purity and sterility were confirmed to pre-set release-criteria (data not shown),cardiopoietic stem cells underwent co-labeling with MPIOs and CM-Dil to facilitate cMRI guided in-vivo and post-mortem cell-tracking (Fig.S2H-K).

Thereafter, random transcatheter, electromechanical-mapping guided intramyocardial transplantation of either cardiopoietic cells or saline (control) was successfully carried out in pigs with post-MI LV-dysfunction ( $n=20$; sub-acute phase; 1-month). While two animals died ( $n=2$; one/group) after the procedure during follow-up due to non-procedural related heartfailure symptoms, all other remaining animals $(n=18)$ successfully completed the planned 30 day follow-up without any adverse-events (Figs.S3A-Q and TbI.S1). Together, these results confirmed that bone marrow derived mesenchymal stem cells could be primed for cardiopoiesis using GMP-compliant methodologies and injected in a large animal heart using state-of-the-art, clinically-relevant, transcatheter techniques.

\section{Cardiopoietic cell therapy improved cardiac-function and attenuated negative LV- remodeling}

The effect of cardiopoietic cell therapy on cardiac-function and maladaptive LV-remodeling was assessed by longitudinal cardiac MRI (cMRI) at day3 (baseline) and 30 days posttransplantation, at day60 (follow-up).

While both groups were comparable at baseline (day3), the ejection-fraction (EF) of treated animals was significantly higher at day60 $(39.2 \% \pm 1.9 \%$ vs. $29.5 \% \pm 2.6 \% ; p=0.012)$ showing a relative EF-increase (relative change to baseline) of $14.0 \% \pm 7.8 \%$, whereas the controls exhibited a relative decrease of $-21.5 \% \pm 5.3 \%(p=0.002)$ (Figs.2A-C and 2J-Q; Tbl.S2 and S3). Next, treated animals also displayed a significant increase in stroke-volume (from $21 \mathrm{ml} \pm 2 \mathrm{ml}$ to $34 \mathrm{ml} \pm 4 \mathrm{ml} ; \quad \mathrm{p}=0.008$ ) and cardiac-output (from $1.7 \mathrm{l} / \mathrm{min} \pm 0.2 \mathrm{l} / \mathrm{min}$ to $3.8 \mathrm{l} / \mathrm{min} \pm 0.5 \mathrm{l} / \mathrm{min} ; \mathrm{p}=0.008)$, with a relative change of $72.5 \% \pm 23.5 \%$ vs. $5.6 \% \pm 11.8 \%$ $(p=0.015)$ and $147.7 \% \pm 51.7 \%$ vs. $27.1 \% \pm 18.3 \%(p=0.047)$ (Fig.2D-I; TbI.S2 and S3).

The evaluation of LV-dimensions in regard to maladaptive LV-remodeling revealed overall better outcomes after cardiopoietic cell therapy (Fig.S4A-O). Unadjusted EDV and ESV were lower (EDV: $87 \mathrm{ml} \pm 8 \mathrm{ml}$ vs. $105 \mathrm{ml} \pm 13 \mathrm{ml} ; p=0.44$ and $E S V: 53 \mathrm{ml} \pm 5 \mathrm{ml}$ vs. $75 \mathrm{ml} \pm 11 \mathrm{ml} ; p=0.10$ ) 
and after adjustment for the increase of total left-ventricular volume (LVMV) (due to animalgrowth during follow-up), this effect was more pronounced. In particular the ESV/LVMV ratio was significantly lower (0.56 \pm 0.04 vs. $0.74 \pm 0.07 ; p=0.027)$ (Fig.S4A-L; TbI.S2) suggesting a reduction in negative LV-remodelling and increased contractility.

These findings indicated that cardiopoietic cells injected shortly after MI may substantially improve cardiac-function and prevent from maladaptive LV-remodeling, thereby ultimately reducing the risk for the development of CHF.

\section{Cardiopoietic cell therapy reduced infarct-size and transmurality}

We then determined the impact of cardiopoietic stem cells upon structural and infarction parameters. Delayed-enhancement $\mathrm{cMRI}$ was used to analyze changes in absolute infarctsize and relative infarct-size as a percentage of LV (relative\% to LV-mass volume; LVMV).

Baseline cMRI (day3) displayed a comparable relative infarct-size $(20.4 \% \pm 1.7 \%$ vs. $20.7 \% \pm 1.4 \% ; p=0.97)$ and absolute infarct-size $(12.3 \mathrm{ml} \pm 1.2 \mathrm{ml}$ vs. $13.4 \mathrm{ml} \pm 1.2 \mathrm{ml} ; \mathrm{p}=0.40)$ confirming a uniform extent of MI between groups (Fig.3A-I; Tbl.S4 and S5). In contrast, at follow-up (day60) and despite comparable LVMV-increase (due to animal-growth), treated animals displayed significantly lower relative (14.1\% $\pm 2.3 \%$ vs. $20.4 \% \pm 1.4 \% ; p=0.043)$ and absolute infarct-sizes $(12.2 \mathrm{ml} \pm 1.9 \mathrm{ml}$ vs. $18.6 \mathrm{ml} \pm 1.1 \mathrm{ml} ; \mathrm{p}=0.012)$ (Fig.3A-I). Longitudinal intra-group analysis revealed a $\sim 30 \%$ reduction in relative infarct-size $(p=0.038)$, that remained unchanged in controls $(p=0.89)$ (Tbl.S5). In line with that, absolute infarct-size significantly increased in the controls $(p=0.012)$, but not after treatment $(p=0.95)$ suggesting effective prevention from infarct-growth (Fig.3A-I; Tbl.S5).

We further performed a detailed investigation on structural-parameters including global and segmental transmurality. Treated animals displayed a reduced global and segmental infarcttransmurality (Fig.3J-S; TbI.S4 and S5) with the largest effect seen in the mid-anterior and mid-anteroseptal segments corresponding to the injection-sites (Fig.4A; Tbl.S6). Additionally, segmental-analysis for contraction-velocity, wall-thickness, and wall-thickening (ES-ED) demonstrated further beneficial effects after treatment (Fig.4B; Tbl.S6-S9). 
Furthermore, in some animals the beneficial cMRI findings could also be further correlated to the NOGA 3D-electromechanical-mapping follow-up analysis at day60. While the nonelectrically conductive infarct-area increased in the controls (measured by a decreased unipolar-voltage), it appeared to remain stable or decrease after treatment (Fig.4C-J). Taken together, these results revealed a comprehensive therapeutic effect on infarct-size, infarcttransmurality and other structural parameters after cardiopoietic cell therapy.

\section{Assessment of intramyocardial retention and cardiopoietic cell-fate after transcatheter}

\section{delivery}

Low retention-rate and the understanding of post-injection cell-fate is, at present, a limiting factor in cell-therapy. Therefore, we performed a comprehensive assessment of intramyocardial retention and fate of cardiopoietic cells post-delivery. Specifically, we first utilized cMRI to track cardiopoietic cells co-labeled with MPIO particles and CM-Dil and then linked and expanded these findings to a comprehensive post-mortem analysis.

In all animals (that had received $\mathrm{MPIO}^{+} / \mathrm{CM}-\mathrm{Dil}^{+}$cardiopoietic stem cells $\mathrm{n}=4$ ), cMRI detected signals of $\mathrm{MPIO}^{+}$cardiopoietic cells in the infarct border-zone of the LV anterior- and septalwall (Fig.5A-I) corresponding with the initial transplantation-sites (region of highest cardiopoietic cell-density) (Fig.5J-N). Interestingly, further analysis showed that the treatment-effect (reduction of infarct-transmurality) overlapped with the transplantation-sites suggesting both; the efficacy of therapy and the accuracy of the NOGA 3Delectromechanical mapping guided intramyocardial delivery (Fig.50-Q).

However, the use of MPIOs to track stem cells on cMRI has been reported to be difficult due to potential phagocytosis of the transplanted cells by macrophages. Therefore, we sought to link the in-vivo cMRI findings to a multi-modal post-mortem analysis comprising of flowcytometry, PCR and immunohistochemistry of representative myocardial-samples taken from the infarct border-zone (injection-sites).

First, cells isolated from myocardial-samples of animals that had received labeled cardiopoietic stem cells $(n=4)$ underwent flow-cytometry targeting the intracellular MPIOs and CM-Dil. In three animals (75\%), few $\mathrm{MPIO}^{+} / \mathrm{CM}-\mathrm{Dil}^{+}$double-positive cardiopoietic cells could 
be detected (Fig.6A). Next, qualitative and quantitative PCR of tissue-samples from the same animals targeting human-specific $\beta 2$-microglobulin and Alu-sequence was performed to further assess intramyocardial integration. Indeed, also in three animals (75\%) human cardiopoietic cells were detected (Fig.6A).

Finally, we then further assessed the fate of the few intramyocardially retained cardiopoietic cells using phase-contrast and fluorescence microscopy and immunohistochemistry (Figs.6B-I and S5A-L). Their intramyocardial presence was verified by double positivity for the Dragongreen fluorochrome-part of the intracellular MPIOs (Fig.6B-G) and humanspecific MHC-1 (Figs.6H-I and S5J). The cells appeared to be heterogeneously distributed in the infarction border-zone and were detectable in the proximity of the myocardial vascularsystem and in the interstitial-spaces. The detected cells appeared to be viable and integrated. Their further characterization showed positive staining for human-specific CD105 confirming their mesenchymal stem-cell origin and, interestingly, few of them also stained positive for a-actinin occasionally (Fig.S5K-L).

Taken together, the in-vivo cell-tracking and post-mortem fate-analysis demonstrated that the amount of intramyocardially integrated cardiopoietic cells appeared to be rather low after 30days suggesting other modes-of-repair to explain the observed therapeutic benefits. Cardiac MRI appeared to be a more robust global detection method as other techniques were exquisitely sensitivity to the specific anatomical location from which the samples were obtained. This is also possibly indicative of limited and heterogeneous retention and biodistribution that could be further confirmed by flow-cytometry and PCR-analysis detecting cardiopoietic cells within the lungs, liver, spleen and kidneys, but not into the bone-marrow (data not shown).

\section{Cardiopioetic cell therapy induced significant neo-angiogenesis and attracts endogenous progenitors}

To further identify potential modes of cardiopoietic cell-induced cardiac-repair, myocardialsamples were further analysed for potential neo-angiogenesis and endogenous stem cell attraction. Consistent with significant cardiopoietic stem cell-induced neo-angiogenesis, 
immunohistochemical analysis revealed a significantly increased density of $\mathrm{vWF}^{+}$vessels in the infarct border-zone (BZ) $\left(176 \pm 7 / \mathrm{mm}^{2}\right.$ vs. $\left.123 \pm 4 / \mathrm{mm}^{2} ; \mathrm{p}=0.003\right)$, but not in the healthy or infarct zone (HZ and IZ, respectively) (Fig.7A-I), Interestingly, significantly higher frequencies (up to 2.5 -fold) of C-kit ${ }^{+}$endogenous progenitor cells were found in the BZ $\left(62.3 \pm 4.5 / \mathrm{mm}^{2} \mathrm{vs}\right.$. $25.2 \pm 3.3 / \mathrm{mm}^{2} ; \mathrm{p}=0.008$ ) (Fig.7J-L) suggesting the activation of an intrinsic repair-response after treatment.

Indeed, these findings supported the notion that even in the presence of limited intramyocardial retention, paracrine modes-of-repair such as neo-angiogenesis and endogenous stem cell recruitment appeared to be the main contributors to the observed therapeutic-effects after cardiopoietic cell therapy.

\section{Intramyocardial cardiopoietic stem cell therapy demonstrates a good safety profile}

Next, we sought to evaluate the safety-profile of cardiopoietic cell therapy in more detail. Longitudinal cardiac-biomarker blood-analysis for Troponin-T, CK, AST, myoglobin and LDH and blood-gas analysis was comparable indicating treatment-safety (Fig.S6A-E and Tbl.S10).

Macroscopically, the explanted hearts of all animals appeared comparable and displayed typical structural characteristics of post re-perfusion necrosis. Transmural-infarctions and significant left-ventricular wall-thinning along with extensive fibrotic scar-formation could be detected in both groups (Fig.8A-E). Two animals presented with an LV-aneurysm formation in the infarct-area and few animals displayed pericardial-adhesions.

We further performed histological analysis of the hearts. Microscopically, both groups were comparable and the infarcted-regions appeared as local-extensive fibro-vascular tissue admixed with inflammatory cells. The endocardium was moderately thickened due to fibrosis and most of the animals displayed a low/moderate degree of chronic inflammation consisting primarily of lymphocytes, some plasma cells and macrophages or seldom giant cells (seldom granuloma-formation). In addition, in few animals of both groups, also small random foci of calcification within the scar were observed, in line with the typical appearance of a chronic MI. Next, few localized lymphocyte aggregations (follicle-formation) were observed in both 
groups. These follicles consisted out of mostly centrally located B-cell (CD20) and randomly distributed T-cells (CD3) being consistent with a classical post MI chronic inflammation and only a limited immune response and/or rejection of the injected cells after 30 days after 30days. Importantly, none of the cell-treated hearts displayed any ectopic tissue- or tumorformation (Fig.S7A-K).

\section{IMPACCT outcome-index quantified therapeutic-effect of cardiopoietic cell therapy}

In order to quantify the observed therapeutic effects of cardiopoietic stem cells, as a final step, we devised a systematic outcome-score, IMPACCT (Integrated $\underline{\text { Multimodal } \text { Potency }}$

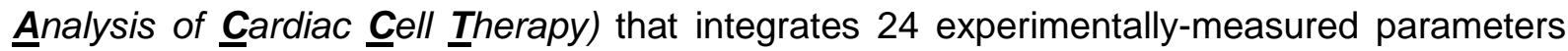
representing cardiac-performance, infarction, structural changes, safety and mode-of-repair (Fig.S8 and Tbl.S11-S15). After treatment, for all five categories a positive effect was detected when compared to the controls: The cardiac-performance index-scores as well as infarction and structural parameters demonstrated a substantial therapeutic-effect. Furthermore, our score indicated a sufficient safety-profile for cardiopoietic stem cells, as judged from cardiac-biomarker serum-levels. Finally, index-scores for parameters targeting modes-of-repair indicated significant therapeutic-effects after cardiopoietic cell therapy

(Fig.S8A). To provide an overall assessment, we further computed composite-scores for each sub-index by taking the mean absolute deviation between the baseline and follow-up scores for each parameter, as well as, for all of the parameter-values combined (Fig.S8B). For the total composite-index score, we calculated un-weighted index-scores, wherein each sub-index score counted equally in the calculation of the total composite IMPACCT-score. Additionally, we also calculated weighted, clinically-oriented index-scores wherein the infarctsize and heart-function sub-indices were assigned greater weight $(x 3)$ to take into consideration their greater predictive clinical-importance (Fig.S8B). Importantly, all subindexes as well as the un-weighted (33.8/100) and weighted (49.5/100) composite IMPACCT-scores indicated a substantial therapeutic-effect after cardiopoietic cell therapy (Fig.S8B). 


\section{Discussion}

\section{Cardiopoietic cell therapy shows safety and efficacy in post-ischemic LV-dysfunction}

Cardiac cell-therapy represents a promising therapeutic-strategy to repair the failing heart [13]. However, although the major part of the available preclinical studies have shown promising results, early clinical-trials have primarily demonstrated heterogeneous outcomes and rather limited efficacy $[1,12]$ highlighting the need for improved, next-generation concepts [1].

As one strategy, the concept of cell lineage-specification through cardiopoietic-guidance has been introduced to enhance the cardioreparative properties of stem cells [16-18] and quickly moved from mice studies to human trials in the setting $\operatorname{CHF}[7,19]$. However, to date, systematic evidence for its therapeutic-efficacy has yet to be reported, no translational, largeanimal data are available, and importantly, little is known about its potential for other clinical indications than CHF.

Therefore, we here provide first clinically-relevant safety and efficacy data of intramyocaridal cardiopoietic stem cell therapy in the treatment of post-ischemic LV-dysfunction. Using a translational pig-model, our data demonstrate the therapeutic potential of cardiopoietic stem cells to preserve cardiac-performance, to limit maladaptive LV-remodeling and to prevent infarct-growth when injected in the subacute phase post-MI. Next, cardiopoietic cell therapy resulted in increased myocardial neo-angiogenesis and activation of endogenous repair mechanisms. Additionally, it showed a good safety-profile in the absence of increased biomarkers for cardiac-events, tumor or ectopic tissue-formation. This raises the intriguing possibility that these cells may efficiently protect against, or at least delay the progression from reversible LV-dysfunction to negative LV-remodeling and subsequent CHF.

Tracking-analysis determines cardiopoietic cell-fate and suggests potential cardiopoietic cell-induced paracrine repair-modes 
Our multimodal in-vivo and post-mortem cell-tracking analysis provided interesting insight into post-delivery cardiopoietic cell-fate and identified potential cardiopoietic cell-induced modes-of-repair.

First, utilizing MPIO-enabled, cMRI guided cell-tracking strategies, our data show that the cMRI-based location of the transplanted cells corresponded to the NOGA-guided transplantation-sites. Importantly and in line with previous reports [25], the injection-sites could also be linked to the observed treatment-effects such as decreased infarct-size and transmurality.

Next, to further determine cardiopoietic cell-fate and to explain the observed functional effects, we linked our in-vivo cMRI findings to a comprehensive post-mortem analysis. Interestingly, flow-cytometry, PCR-analysis and immunohistochemistry showed that only few cardiopoietic cells had integrated into the myocardium, while the major fraction of injected cells appeared to have homed in other organs [19]. This is an important finding as our data suggest that the observed beneficial effects of cardiopoietic cell treatment seem not to be attributed to intramyocardial engraftment, but instead, appear to be primarily driven by paracrine mechanisms.

The principal capacity of naïve bone-marrow MSCs to induce neoangiogenesis is well established, but has also been reported to heterogeneous and to vary between patients $[1,8$, 13, 19, 26]. When derived from CHF patients, naïve bone-marrow derived MSCs often demonstrated latent plasticity with variable spontaneous capacity to induce regeneration [1, $8,13,19]$. Therefore, the induction of cardiopoiesis is intended to upgrade cardioreparative properties of bone-marrow derived MSCs and is promoted through replication of natural cues decoded from endoderm-mediated cardiogenic guidance of the mesoderm $[17,19]$.

In this study, we detected two primary mechanisms of cardiopoietic cell-induced paracrinerepair that is the significant induction of neo-agiogenesis and the attraction $\mathrm{C}$-Kit ${ }^{+}$progenitors into the infarcted myocardium.

First, the human GMP-grade cardiopoietic stem cells used in this study demonstrated a high and homogenous potential for neo-angiogenesis in-vitro and in-vivo. This was documented 
though the tube-formation assay prior to transplantation and was then further validated invivo by a significantly increased von Willebrand Factor ${ }^{+}$vessel-density in the infarct borderzone post-treatment. Second, significant cardiopoietic stem cell-induced attraction of endogenous $\mathrm{C}-\mathrm{Kit}^{+}$progenitors into the infarct border-zone was detected, being consistent with previous reports [27-29]. Taken together, our comprehensive cardiopoietic cell-fate analysis provides valuable insight and a mechanistic basis to explain the observed therapeutic-effect after treatment. This effect can be proposed as an initial paracrine driven cardio-protection (prevention from maladaptive LV-remodelling and subsequent development of $\mathrm{CHF}$ ), which is then followed by functional-recovery ultimately resulting in an improved overall cardiac-performance.

\section{Improving quality-standards of cell-based therapies towards clinical-translation}

While it is not unusual for promising preclinical studies to fail the translation into the clinicalsetting, in the case of cell therapy we also noted a lack of sufficient comparability in the methodologies and evaluations utilized in preclinical and clinical studies. We addressed this problem by adopting a fully translational pipeline in our study, including GMP-grade cell manufacturing, the use of clinical-grade methodologies (e.g. randomization, blinding and standardized evaluation protocols) and the incorporation of a clinically-relevant animalmodel. Additionally, to facilitate a quantitative comparison between trials that can specifically address the multi-faceted aspects of cardiac disease and -repair, we also implemented a standardized therapeutic outcome-metric (IMPACCT) that may offer an improved assessment of cardiac cell-therapies. Both, our un-weighted and weighted clinically-oriented IMPACCT-scores substantiated the observed therapeutic-effect of cardiopoietic cell therapy. Of note, the recently updated position paper of the European Society of Cardiology (ESC) Working Group Cellular Biology of the Heart [14] calls for standardized methodologies and quality control in order to ensure regenerative proficiency in next-generation cardiac cell therapy concepts [30, 31] In this context, analysis tools, such as IMPACCT, may be helpful to better objectify sets of observations, quantitatively compare them across various groups, and 
easily visualize quality information related to stem cells [32] and their true potential to regenerate the heart.

\section{Limitations}

There are several limitations in our study: First, using human cells in our porcine model required immunosuppressive-therapy which may potentially influence the outcome. However, an optimized and cell-specific treatment-regime was applied to minimize this problem. However, an efficient dosage of our treatment-regime was assumed as there was comparability between groups with regards to the observed post-MI chronic inflammation and immune-response. Second, the utilization of super-paramagnetic agents (i.e. the used MPIOs) has been repeatedly argued as it is difficult to discriminate between vital target cells and phagocytosing cells that may have incorporated the particles after cell-death. Third, considering our multimodal cell-tracking approach comprising Flow-Cytometry, PCR and $\mathrm{IHC}$, the results on intramyocardial retention and bio-distribution may be influenced by the exact location (border-zone of MI) from which the analyzed myocardial tissue-samples were obtained. Fourth, although our proposed IMPACCT-score may be a valuable tool, further validation ideally using large clinical-cohorts is needed. Finally, our findings need to be further validated in long-term investigations.

\section{Conclusions}

This report demonstrates for the first time the efficacy and safety of human cardiopoietic stem cells in the treatment of post-infarction LV-dysfunction using a translational large animal-model. When injected in the sub-acute phase of $\mathrm{Ml}$, cardiopoietic cell therapy appears to provide a substantial cardioprotective effect, followed by functional recovery ultimately preventing maladaptive LV-remodeling and subsequent progression to CHF. The overall intramyocardial integration of cardiopoietic cells appears to be limited. Thus, the observed beneficial-effects seem to be primarily driven by paracrine mechanisms including 
the significant induction of neo-angiogenesis, and the attraction endogenous stem cells. The usage of a rigorous preclinical trial-design and implementation of a systematic quality-metric may contribute to a better objectification of the observed therapeutic-effects. In view of the "translational readiness", our data may build the basis for further validation in a phase-I clinical-trial targeting patients with post-ischemic LV-dysfunction, thereby broadening the current CHF indication of this interesting next-generation cell-type.

\section{Acknowledgments}

We thank Peter De Weale, Aymeric Seron, Dorothee Daro and Sebastien Mauen from Celyad/Belgium for the generation of GMP-grade human cardiopoietic stem cells; Stefan Schwyter for graphical-support and Dr. Fischer from Biosense Webster; USA for support on the NOGA-procedures; Microsynth AG; Switzerland and Sophistolab; Switzerland for support on qPCR and immunohistochemistry; Ladina Ettinger-Ferguson, Kati Zlinszki and Agnieszka Karol from the Vetsuisse Faculty Zurich for support on immunohistochemistry.

\section{Funding}

This study was funded by institutional grants of the University of Zurich. M.Y.E. was supported by the Swiss National Science Foundation (SNSF), the Swiss Heart Foundation and the Olga-Mayenfisch Foundation. S.P.S. and K.K.P. acknowledge funding support from National Heart Lung and Blood Institute grant U01 HL100408. 


\section{References}

1. Behfar A, Crespo-Diaz R, Terzic A, and Gersh BJ. Cell therapy for cardiac repair--lessons from clinical trials. Nat Rev Cardiol. 2014. 11(4): 232-46.

2. Emmert MY, Hitchcock RW, and Hoerstrup SP. Cell therapy, 3D culture systems and tissue engineering for cardiac regeneration. Adv Drug Deliv Rev. 2014. 69-70: 254-69.

3. Segers VF and Lee RT. Stem-cell therapy for cardiac disease. Nature. 2008. 451(7181): 937942.

4. van der Spoel TI, Jansen of Lorkeers SJ, Agostoni P, van Belle E, Gyongyosi M, Sluijter JP, Cramer MJ, Doevendans PA, and Chamuleau SA. Human relevance of pre-clinical studies in stem cell therapy: systematic review and meta-analysis of large animal models of ischaemic heart disease. Cardiovasc Res. 2011. 91(4): 649-58.

5. Jansen Of Lorkeers SJ, Eding JE, Vesterinen HM, van der Spoel TI, Sena ES, Duckers HJ, Doevendans PA, Macleod MR, and Chamuleau SA. Similar effect of autologous and allogeneic cell therapy for ischemic heart disease: systematic review and meta-analysis of large animal studies. Circ Res. 2015. 116(1): 80-6.

6. Zwetsloot PP, Vegh AM, Jansen Of Lorkeers SJ, van Hout GP, Currie GL, Sena ES, Gremmels H, Buikema JW, Goumans MJ, Macleod MR, Doevendans PA, Chamuleau SA, and Sluijter JP. Cardiac Stem Cell Treatment in Myocardial Infarction: A Systematic Review and MetaAnalysis of Preclinical Studies. Circ Res. 2016. 118(8): 1223-32.

7. Bartunek J, Behfar A, Dolatabadi D, Vanderheyden M, Ostojic M, Dens J, El Nakadi B, Banovic M, Beleslin B, Vrolix M, Legrand V, Vrints C, Vanoverschelde JL, Crespo-Diaz R, Homsy C, Tendera M, Waldman S, Wijns W, and Terzic A. Cardiopoietic stem cell therapy in heart failure: the C-CURE (Cardiopoietic stem Cell therapy in heart failURE) multicenter randomized trial with lineage-specified biologics. J Am Coll Cardiol. 2013. 61(23): 2329-38.

8. Hare JM, Fishman JE, Gerstenblith G, DiFede Velazquez DL, Zambrano JP, Suncion VY, Tracy $M$, Ghersin E, Johnston PV, Brinker JA, Breton E, Davis-Sproul J, Schulman IH, Byrnes J, Mendizabal AM, Lowery MH, Rouy D, Altman P, Wong Po Foo C, Ruiz P, Amador A, Da Silva J, McNiece IK, Heldman AW, George R, and Lardo A. Comparison of allogeneic vs autologous bone marrow-derived mesenchymal stem cells delivered by transendocardial injection in patients with ischemic cardiomyopathy: the POSEIDON randomized trial. JAMA. 2012. 308(22): 2369-79.

9. Makkar RR, Smith RR, Cheng K, Malliaras K, Thomson LE, Berman D, Czer LS, Marban L, Mendizabal A, Johnston PV, Russell SD, Schuleri KH, Lardo AC, Gerstenblith G, and Marban E. Intracoronary cardiosphere-derived cells for heart regeneration after myocardial infarction (CADUCEUS): a prospective, randomised phase 1 trial. Lancet. 2012. 379(9819): 895-904.

10. Schachinger V, Erbs S, Elsasser A, Haberbosch W, Hambrecht R, Holschermann H, Yu J, Corti R, Mathey DG, Hamm CW, Suselbeck T, Assmus B, Tonn T, Dimmeler S, and Zeiher AM. Intracoronary bone marrow-derived progenitor cells in acute myocardial infarction. N Engl J Med. 2006. 355(12): 1210-21.

11. Surder D, Manka R, Lo Cicero V, Moccetti T, Rufibach K, Soncin S, Turchetto L, Radrizzani M, Astori G, Schwitter J, Erne P, Zuber M, Auf der Maur C, Jamshidi P, Gaemperli O, Windecker S, Moschovitis A, Wahl A, Buhler I, Wyss C, Kozerke S, Landmesser U, Luscher TF, and Corti R. Intracoronary injection of bone marrow-derived mononuclear cells early or late after acute myocardial infarction: effects on global left ventricular function. Circulation. 127(19): 196879.

12. Gyongyosi $M$, Wojakowski W, Lemarchand $P$, Lunde $K$, Tendera $M$, Bartunek J, Marban $E$, Assmus B, Henry TD, Traverse JH, Moye LA, Surder D, Corti R, Huikuri H, Miettinen J, Wohrle J, Obradovic S, Roncalli J, Malliaras K, Pokushalov E, Romanov A, Kastrup J, Bergmann MW, Atsma DE, Diederichsen A, Edes I, Benedek I, Benedek T, Pejkov H, Nyolczas N, Pavo N, Bergler-Klein J, Pavo IJ, Sylven C, Berti S, Navarese EP, Maurer G, and Investigators* A. MetaAnalysis of Cell-based CaRdiac stUdiEs (ACCRUE) in Patients With Acute Myocardial Infarction Based on Individual Patient Data. Circ Res. 2015. 116(8): 1346-60. 
13. Marban E and Malliaras K. Mixed results for bone marrow-derived cell therapy for ischemic heart disease. JAMA. 2012. 308(22): 2405-6.

14. Madonna R, Van Laake LW, Davidson SM, Engel FB, Hausenloy DJ, Lecour S, Leor J, Perrino C, Schulz R, Ytrehus K, Landmesser U, Mummery CL, Janssens S, Willerson J, Eschenhagen T, Ferdinandy P, and Sluijter JP. Position Paper of the European Society of Cardiology Working Group Cellular Biology of the Heart: cell-based therapies for myocardial repair and regeneration in ischemic heart disease and heart failure. Eur Heart J. 2016.

15. Schussler-Lenz M, Beuneu C, Menezes-Ferreira M, Jekerle V, Bartunek J, Chamuleau S, Celis $P$, Doevendans $P$, O'Donovan M, Hill J, Hystad M, Jovinge S, Kyselovic J, Lipnik-Stangelj M, Maciulaitis R, Prasad K, Samuel A, Tenhunen O, Tonn T, Rosano G, Zeiher A, and Salmikangas P. Cell-based therapies for cardiac repair: a meeting report on scientific observations and European regulatory viewpoints. Eur J Heart Fail. 2016. 18(2): 133-41.

16. Behfar A, Faustino RS, Arrell DK, Dzeja PP, Perez-Terzic C, and Terzic A. Guided stem cell cardiopoiesis: discovery and translation. J Mol Cell Cardiol. 2008. 45(4): 523-9.

17. Behfar A and Terzic A. Derivation of a cardiopoietic population from human mesenchymal stem cells yields cardiac progeny. Nat Clin Pract Cardiovasc Med. 2006. 3 Suppl 1: S78-82.

18. Marban E and Malliaras K. Boot camp for mesenchymal stem cells. J Am Coll Cardiol. 2010. 56(9): 735-7.

19. Behfar A, Yamada S, Crespo-Diaz R, Nesbitt JJ, Rowe LA, Perez-Terzic C, Gaussin V, Homsy C, Bartunek J, and Terzic A. Guided cardiopoiesis enhances therapeutic benefit of bone marrow human mesenchymal stem cells in chronic myocardial infarction. J Am Coll Cardiol. 2010. 56(9): 721-34.

20. Emmert MY, Wolint $P$, Winklhofer S, Stolzmann $P$, Cesarovic N, Fleischmann T, Nguyen TD, Frauenfelder T, Boni R, Scherman J, Bettex D, Grunenfelder J, Schwartlander R, Vogel V, Gyongyosi M, Alkadhi H, Falk V, and Hoerstrup SP. Transcatheter based electromechanical mapping guided intramyocardial transplantation and in vivo tracking of human stem cell based three dimensional microtissues in the porcine heart. Biomaterials. 2013. 34(10): 242841.

21. McCall FC, Telukuntla KS, Karantalis V, Suncion VY, Heldman AW, Mushtaq M, Williams AR, and Hare JM. Myocardial infarction and intramyocardial injection models in swine. Nat Protoc. 2012. 7(8): 1479-96.

22. Templin C, Zweigerdt R, Schwanke K, Olmer R, Ghadri JR, Emmert MY, Muller E, Kuest SM, Cohrs S, Schibli R, Kronen P, Hilbe M, Reinisch A, Strunk D, Haverich A, Hoerstrup S, Luscher $\mathrm{TF}$, Kaufmann PA, Landmesser $\mathrm{U}$, and Martin U. Transplantation and tracking of humaninduced pluripotent stem cells in a pig model of myocardial infarction: assessment of cell survival, engraftment, and distribution by hybrid single photon emission computed tomography/computed tomography of sodium iodide symporter transgene expression. Circulation. 2012. 126(4): 430-9.

23. Gyongyosi M and Dib N. Diagnostic and prognostic value of 3D NOGA mapping in ischemic heart disease. Nat Rev Cardiol. 2011. 8(7): 393-404.

24. Jansen Of Lorkeers SJ, Hart E, Tang XL, Chamuleau ME, Doevendans PA, Bolli R, and Chamuleau SA. Cyclosporin in cell therapy for cardiac regeneration. J Cardiovasc Transl Res. 2014. 7(5): 475-82.

25. Suncion VY, Ghersin E, Fishman JE, Zambrano JP, Karantalis V, Mandel N, Nelson KH, Gerstenblith G, DiFede Velazquez DL, Breton E, Sitammagari K, Schulman IH, Taldone SN, Williams AR, Sanina C, Johnston PV, Brinker J, Altman P, Mushtaq M, Trachtenberg B, Mendizabal AM, Tracy M, Da Silva J, McNiece IK, Lardo AC, George RT, Hare JM, and Heldman AW. Does transendocardial injection of mesenchymal stem cells improve myocardial function locally or globally?: An analysis from the Percutaneous Stem Cell Injection Delivery Effects on Neomyogenesis (POSEIDON) randomized trial. Circ Res. 2014. 114(8): 1292-301.

26. Crespo-Diaz R, Yamada S, Bartunek J, Perez-Terzic C, de Waele P, Mauen S, Terzic A, and Behfar A. Cardiopoietic index predicts heart repair fitness of patient-derived stem cells. Biomark Med. 2015. 9(7): 639-49. 
27. Karantalis V, Suncion-Loescher VY, Bagno L, Golpanian S, Wolf A, Sanina C, Premer C, Kanelidis AJ, McCall F, Wang B, Balkan W, Rodriguez J, Rosado M, Morales A, Hatzistergos K, Natsumeda M, Margitich I, Schulman IH, Gomes SA, Mushtaq M, DiFede DL, Fishman JE, Pattany P, Zambrano JP, Heldman AW, and Hare JM. Synergistic Effects of Combined Cell Therapy for Chronic Ischemic Cardiomyopathy. J Am Coll Cardiol. 2015. 66(18): 1990-9.

28. Williams AR, Hatzistergos KE, Addicott B, McCall F, Carvalho D, Suncion V, Morales AR, Da Silva J, Sussman MA, Heldman AW, and Hare JM. Enhanced effect of combining human cardiac stem cells and bone marrow mesenchymal stem cells to reduce infarct size and to restore cardiac function after myocardial infarction. Circulation. 2013. 127(2): 213-23.

29. Hatzistergos KE, Quevedo H, Oskouei BN, Hu Q, Feigenbaum GS, Margitich IS, Mazhari R, Boyle AJ, Zambrano JP, Rodriguez JE, Dulce R, Pattany PM, Valdes D, Revilla C, Heldman AW, McNiece I, and Hare JM. Bone marrow mesenchymal stem cells stimulate cardiac stem cell proliferation and differentiation. Circ Res. 2010. 107(7): 913-22.

30. Terzic A and Behfar A. Stem cell therapy for heart failure: Ensuring regenerative proficiency. Trends Cardiovasc Med. 2016. 26(5): 395-404.

31. Terzic A, Behfar A, and Filippatos G. Clinical development plan for regenerative therapy in heart failure. Eur J Heart Fail. 2016. 18(2): 142-4.

32. Sheehy SP, Pasqualini F, Grosberg A, Park SJ, Aratyn-Schaus Y, and Parker KK. Quality metrics for stem cell-derived cardiac myocytes. Stem Cell Reports. 2014. 2(3): 282-94. 


\section{Legends}

Fig.1: Study flow-chart $(\mathrm{A})$ and randomized transcatheter electromechanical mapping guided NOGA stem cell injection (B)

Fig.2: Cardiopoietic stem cell therapy improves cardiac-performance. While both groups were comparable at baseline cMRI (day3 post-infarction), the EF of treated animals was significantly higher at follow-up (day60) (A and B) with a substantial relative EF-increase after cardiopoietic stem cell therapy, while controls showed a relative decrease (C). Treated animals displayed a significantly increased SV and CO while controls did not (D-I). Enddiastolic (J,L,N and $\mathbf{P})$ and end-systolic (K,M,O and $\mathbf{Q})$ short-axis images out of which the EF was determined by the ratio of end-diastolic to end-systolic volumes (red outline-segments) were acquired using standard SSFP cine-MRI techniques at baseline (day3) and follow-up (day60). While the EF deteriorated in controls (J-M), it improved after cardiopoietic stem cell therapy during follow-up (N-Q). ${ }^{*} p<0.05$ vs. control; ${ }^{* *} p<0.01$ vs. control; $t p<0.05$ follow-up vs. baseline control; $\boldsymbol{\$} p<0.05$ follow-up vs. baseline treated (see tables S2/S3).

Fig.3: Cardiopoietic stem cell therapy prevents infarct-growth and reduces infarcttransmurality. While both groups were comparable at baseline (day3), treated animals showed significantly lower relative (relative\% to LVMV) and absolute infarct-sizes at followup (day60) (A-C). Intra-group-analysis showed a significant increase of absolute infarct-size in control animals at follow-up, while it remained unchanged after therapy indicating effective mitigation of infarct-growth ( $\mathbf{D}$ and $\mathbf{E}$ ). Global infarct-transmurality was reduced after cardiopoietic stem cell therapy (G-I). Representative cMRI infarct-segmentation (J-M; semiautomatic delineation of $\mathrm{Ml}$ (yellow) illustrates a reduced scar-volume after treatment ( $\mathrm{L}$ and $\mathbf{M})$, but not in the control ( $\mathbf{J}$ and $\mathbf{K}$ ) at FU (day 60). Representative longitudinal lateenhancement analysis at 12 hours, 8 days and 30 days displayed a continuous decrease of 
infarct-transmurality after cardiopoietic stem cell therapy (N-P) along with an increasing myocardial-viability in the corresponding segments (Q-S). ${ }^{*} p<0.05$ vs. control; ${ }^{\star *} p<0.01$ vs. control; $t p<0.05$ follow-up vs. baseline control; $\$ p<0.05$ follow-up vs. baseline treated; $\ddagger p=0.10$ vs. control; $¥ p=0.07$ vs. control (see tables S4/S5).

Fig.4: Cardiac MRI based segmental-analysis and 3D-NOGA electromechanicalmapping assessment after cardiopoietic stem cell therapy. Representative cMRI segmental-analysis of infarct-transmurality and contraction-velocity demonstrated beneficialeffects after cardiopoietic stem cell therapy with the largest effect in the mid-anterior and midanteroseptal segments corresponding with the injection-sites (A and B;blue hues, black arrows), while no effect or deterioration was seen in controls. Representative 3D-NOGA electromechanical-mapping analysis showed that the infarct-area (red hues; low unipolarvoltage $(\mathrm{mV})$ ) was comparable at transplantation (day30) (C-J). In contrast, at follow-up (day60) infarct-area increased in control (I-L), while it decreased after therapy (C-J). 3Dviews of LV derived by NOGA-mapping and NOGA-guided intramyocardial cardiopoietic stem cell delivery. Color-coded 3D-images (C,E,G and I) were converted into a 2D polarmap (bull-eye view;D,F,H and J). Color-codes: Red=non-viable infarcted myocardium; Green/Yellow=border-zone of infarction (injection-area); Blue/Purple=normal viable myocardium.

Fig.5: Cardiac MRI guided in-vivo monitoring of cardiopoietic stem cells displays the relation between transplantation-sites, infarction-zone and localization of treatmenteffect. In-vivo monitoring of labeled cardiopoietic stem cells was performed using MPIOs for cMRI-guided tracking in four animals $(n=4) .2 D$ and 3D-reconstruction images of a representative animal show clusters of cardiopoietic stem cells in the MI border-zone appearing as dark regions (white arrows) of strong focal signal-loss at 12hours (A-C), 8days (D-F) and 30days (G-I) post-delivery. Importantly, the highest cell-density (transplantation- 
sites) exactly corresponds with the infarction border-zone ( $\mathbf{J}$ and $\mathbf{K}$;asterix) leading to a reduction of infarct-transmurality at follow-up (30days post-injection) (L-N;white arrows). Further optical-overlay confirms that the highest treatment-effect (black arrows/blue hue: reduction of infarct-transmurality) is exactly overlapping with the highest cell-density strongly suggesting both; the efficacy of cardiopoietic stem cell therapy and the accuracy of 3DNOGA guided intramyocardial-delivery (O-Q;black arrows).

Fig.6: Cardiopoietic stem cell tracking, fate analysis and post-mortem macroscopy. To assess intramyocardial integration and cardiopoietic stem cell fate, cMRI-guided MPIOenabled in-vivo cell tracking analysis (see also figure 5) was linked to a multimodal postmortem evaluation including Flow-Cytometry and PCR. In all animals that had received $\mathrm{MPIO}^{+} / \mathrm{CM}-\mathrm{Dil}^{+}$cardiopoietic stem cells, cMRI analysis detected clusters of $\mathrm{MPIO}^{+}$ cardiopoietic stem cells intramyocardially $(n=4,100 \%)$. Next, both, flow-cytometry targeting the Dragongreen fluorochrome-part of the intracellular MPIOs and/or CM-Dil and PCR targeting human-specific $\beta 2$-microglobulin and/or Alu-sequence showed positivity in three animals $(n=3,75 \%)$ and confirmed intramyocardial integration of cardiopoietic stem cells (A). In addition, further phase-contrast, fluorescence-analysis (B-G) and immunohistochemistry (H and I) further verified intramyocardial integration by positive staining for the Dragongreen fluorochrome-part of the MPIOs (E-G and I inset; arrowheads) and human-specific MHC-1 (H and I).

Fig.7: Cardiopioetic stem cell therapy induces neo-angiogenesis and attracts endogenous stem cells. Neo-angiogenesis was assessed 30days post-delivery by immunohistochemical-analysis for $\operatorname{CD} 31$ (A) and vWF (B-I). vWF ${ }^{+}$vessel-density in the infarct border-zone (BZ) was significantly higher in treated animals (C-I). Similarly, the attraction of $\mathrm{C}-\mathrm{kit}^{+}$endogenous progenitors was significantly higher (up to 2.5 -fold) in the BZ 
after cardiopoietic cell stem therapy (J-L). ${ }^{*} p=0.003$ vs. control; ${ }^{* *} p=0.008$ vs. control. Scalebars: 10um.

Fig.8: Gross examination of myocardium displays safety of cardiopoietic cell therapy. Post-mortem macroscopy displayed the typical structural-characteristics of post-reperfusion necrosis and remodeling (J-N). Uniform anterior-septal transmural-infarctions along with leftventricular wall-thinning and fibrotic scar-formation were detectable in both groups $(\mathbf{J}-\mathbf{L})$ further confirmed by UV-imaging (M) and Van-Giemsa staining of a whole LV cross-section (N). $H Z=$ healthy zone, $B Z=$ infarct border-zone, IZ=infarct zone. Scale-bars: $50 u m$ (B-G) and 10um ( $H$ and l;insets). 
Figure 1:

A

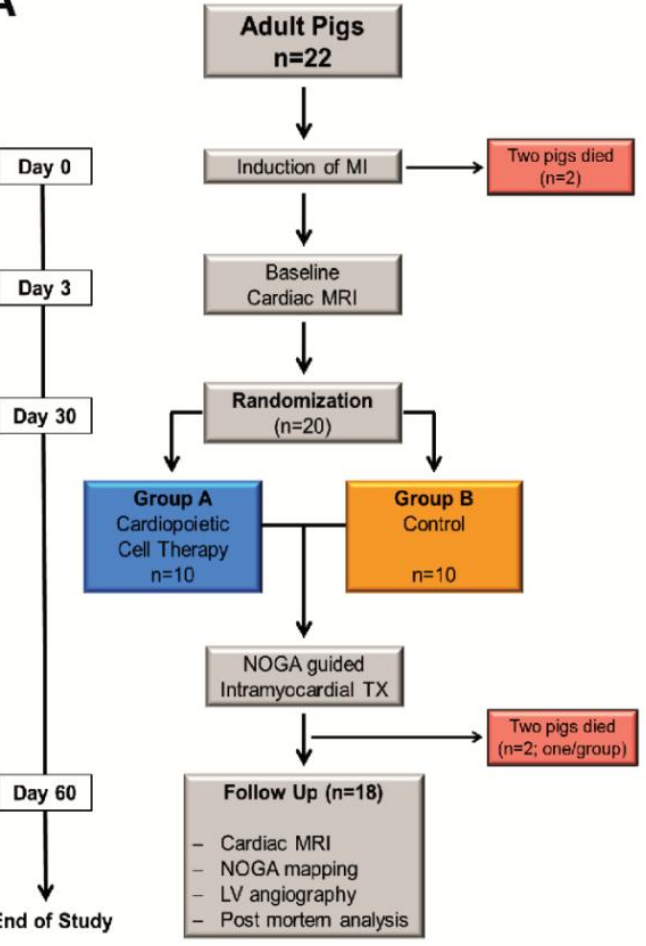

B

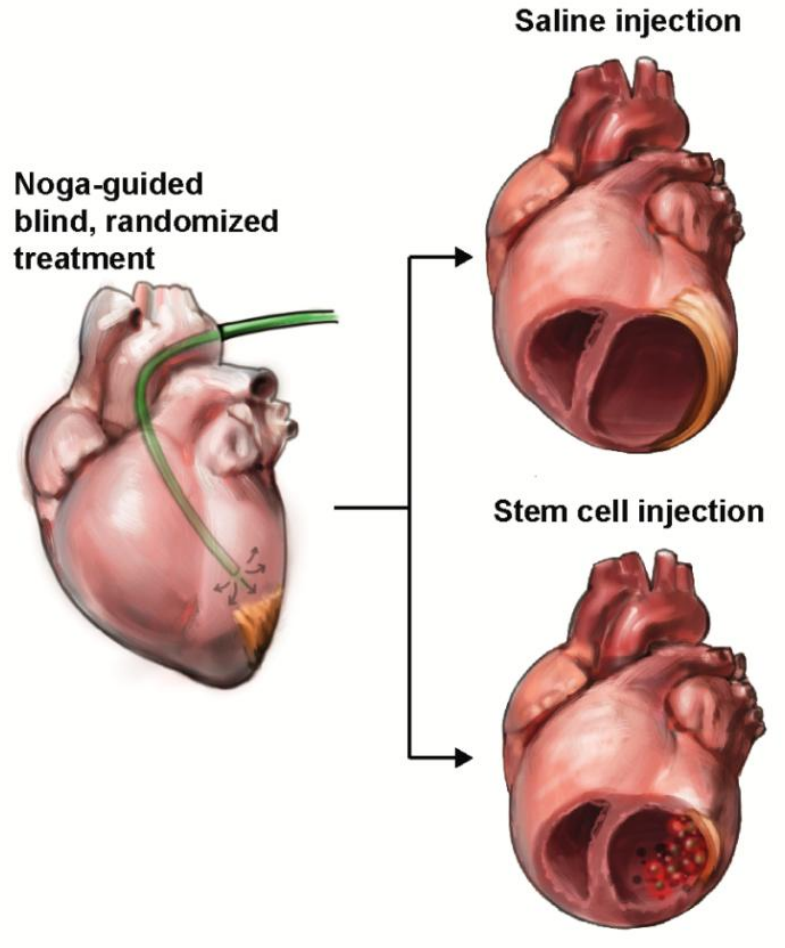


Figure 2:

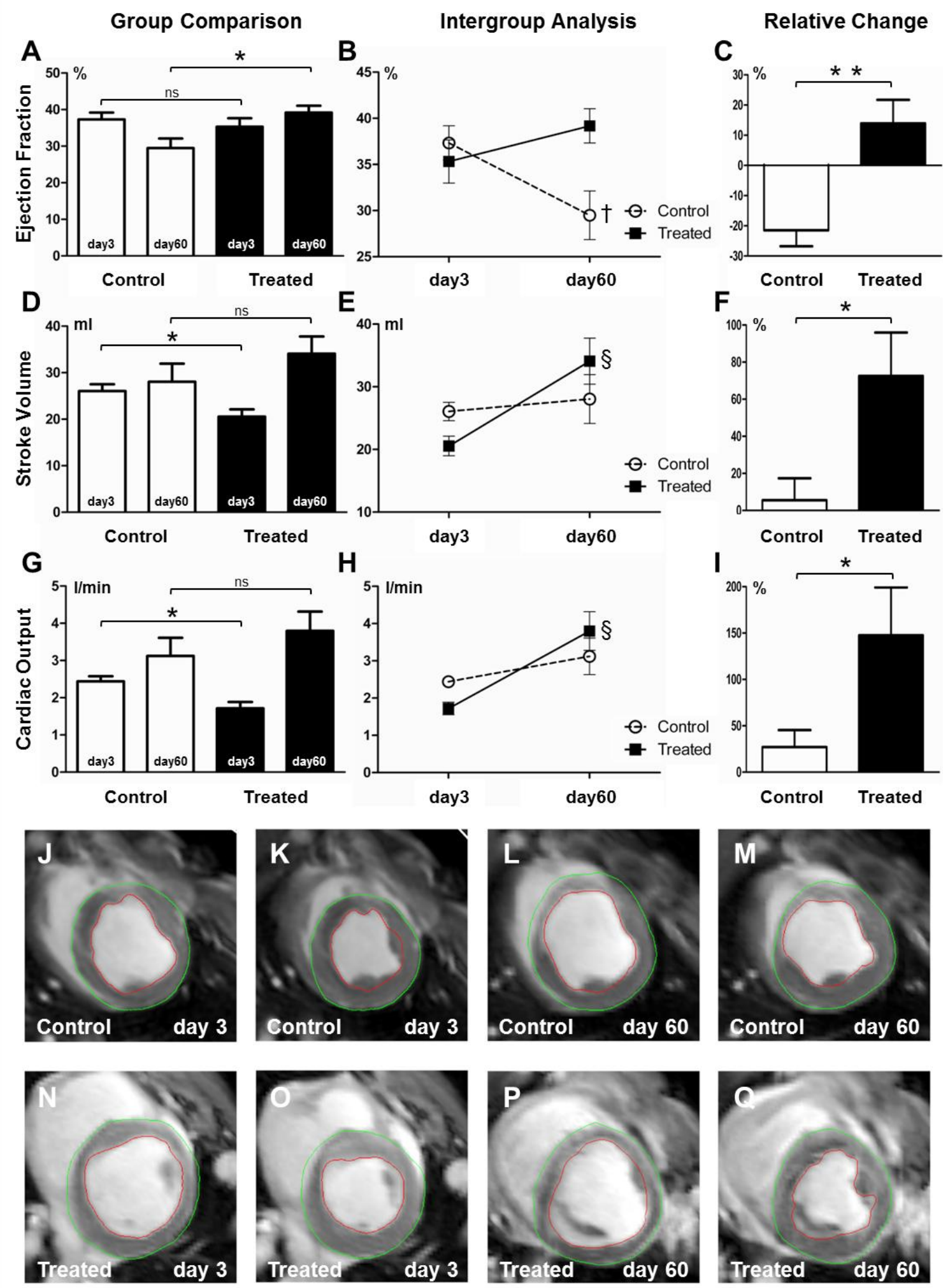


Figure 3:
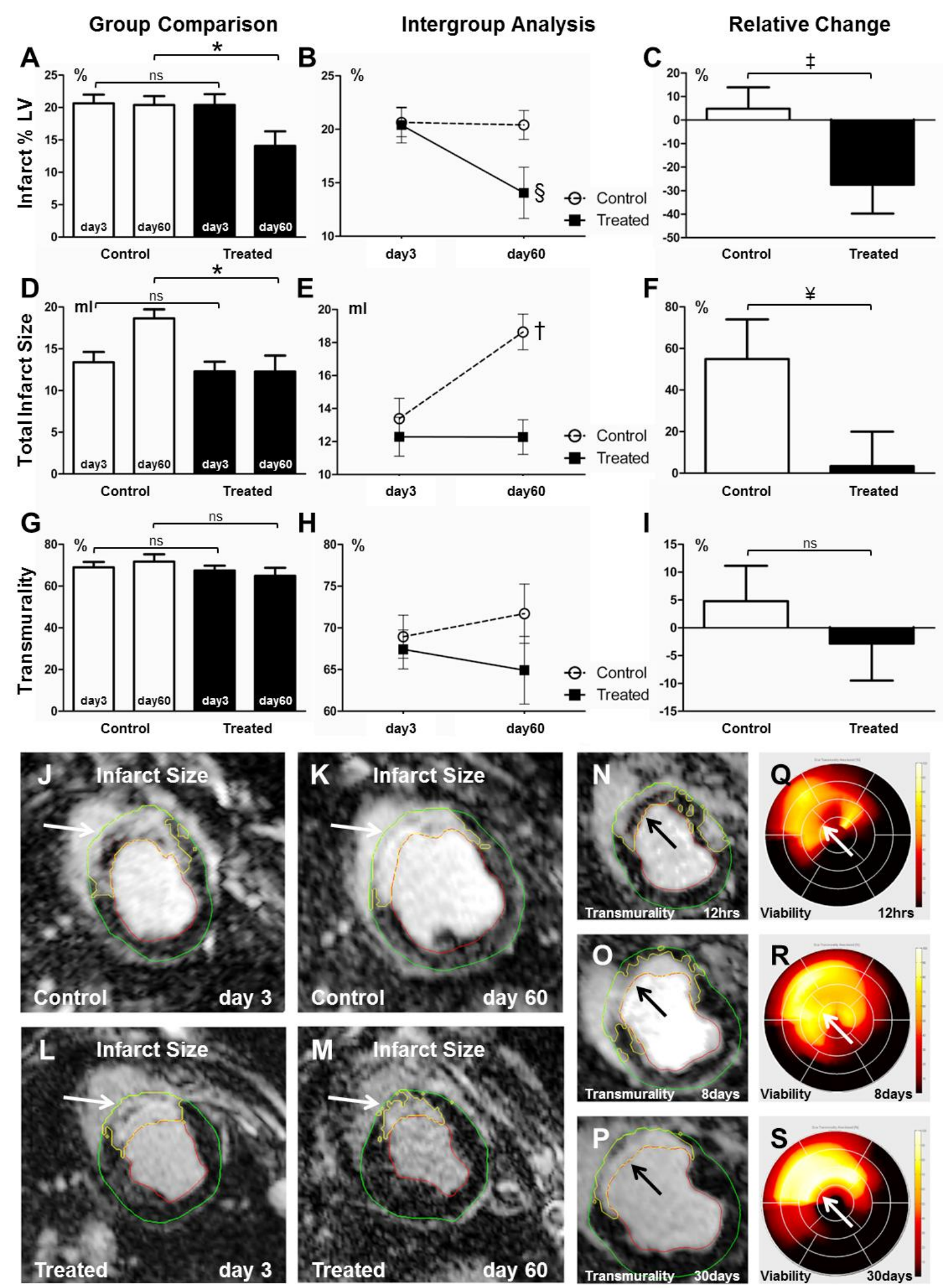
Figure 4:

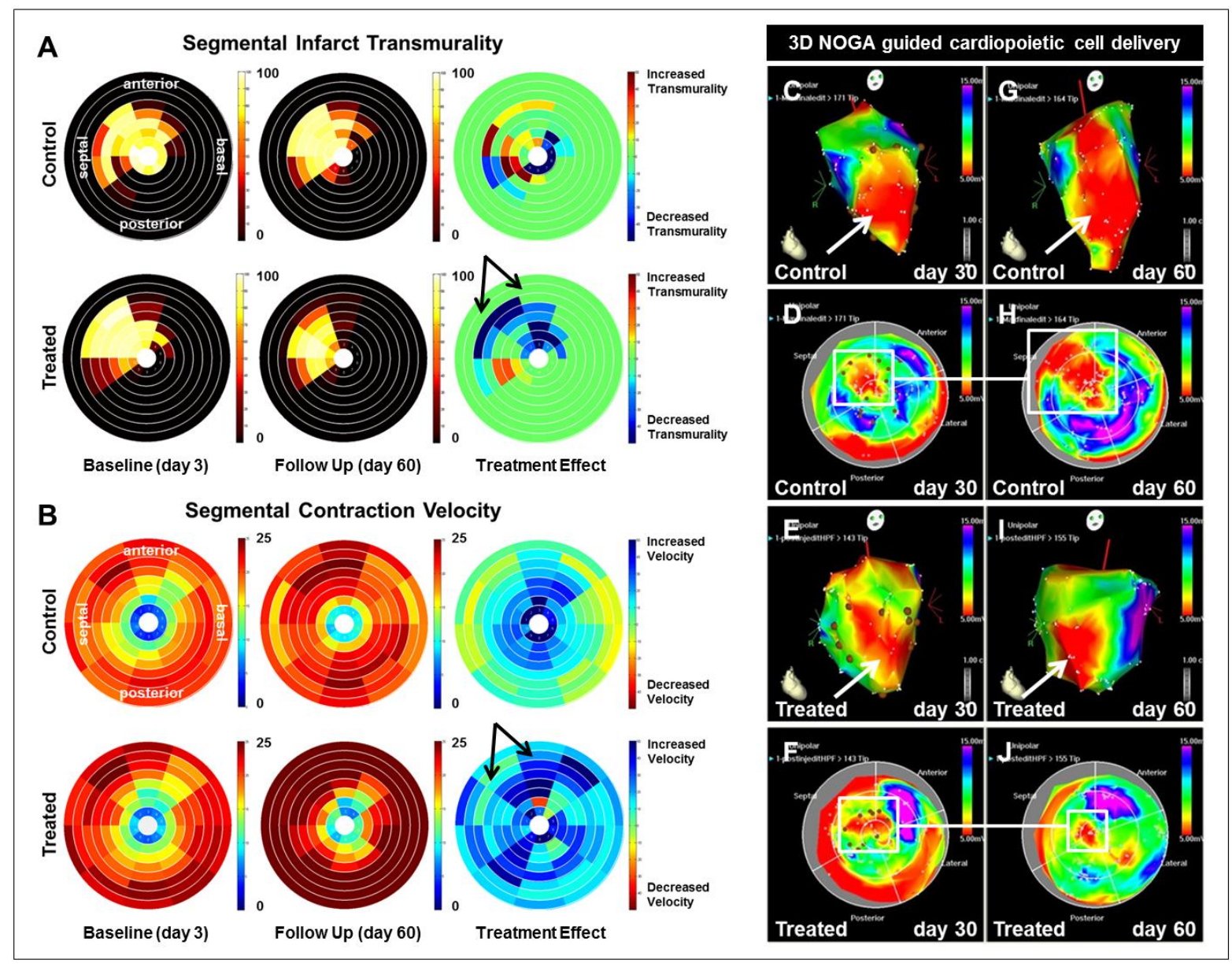


Figure 5:
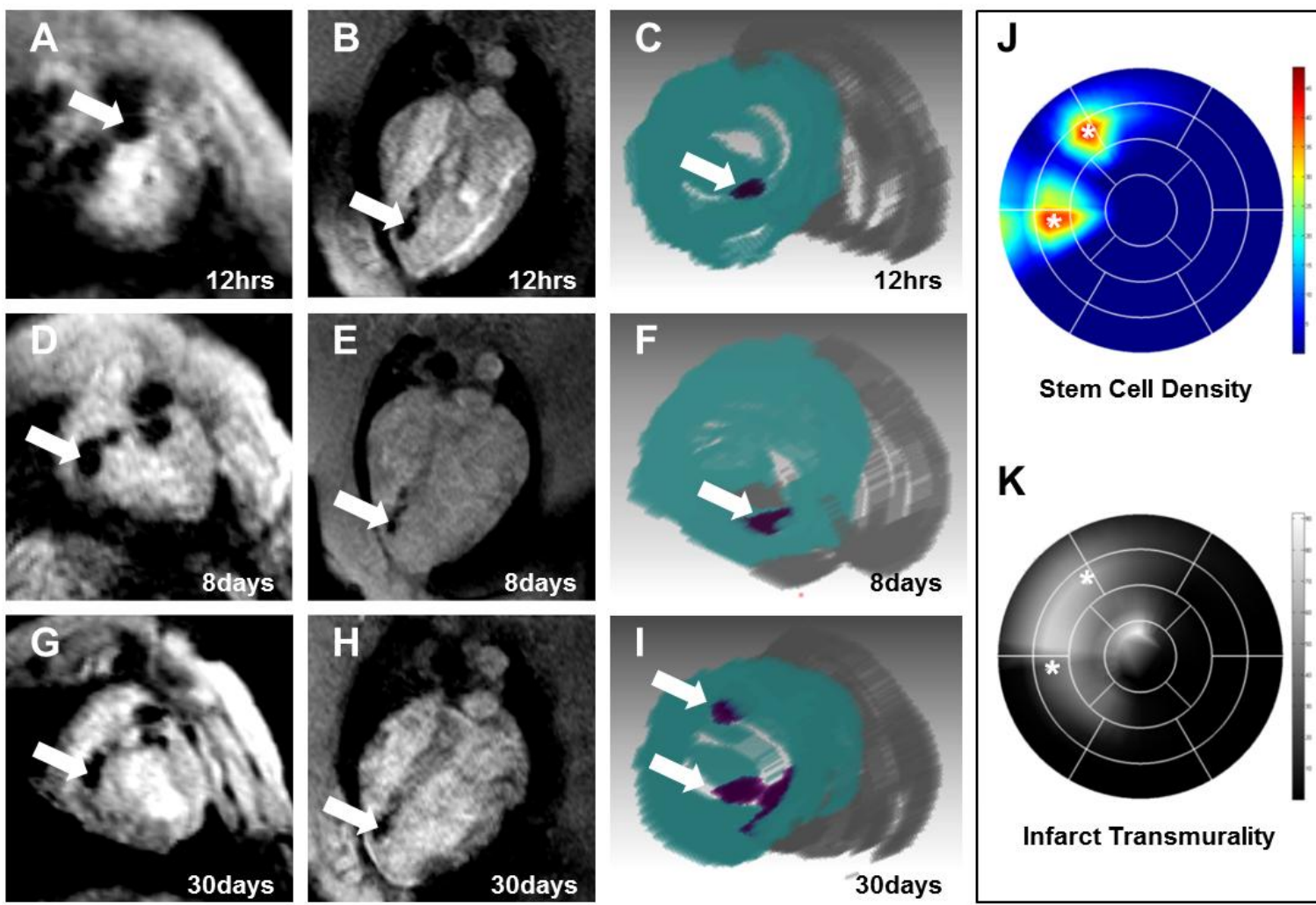

Infarct Transmurality
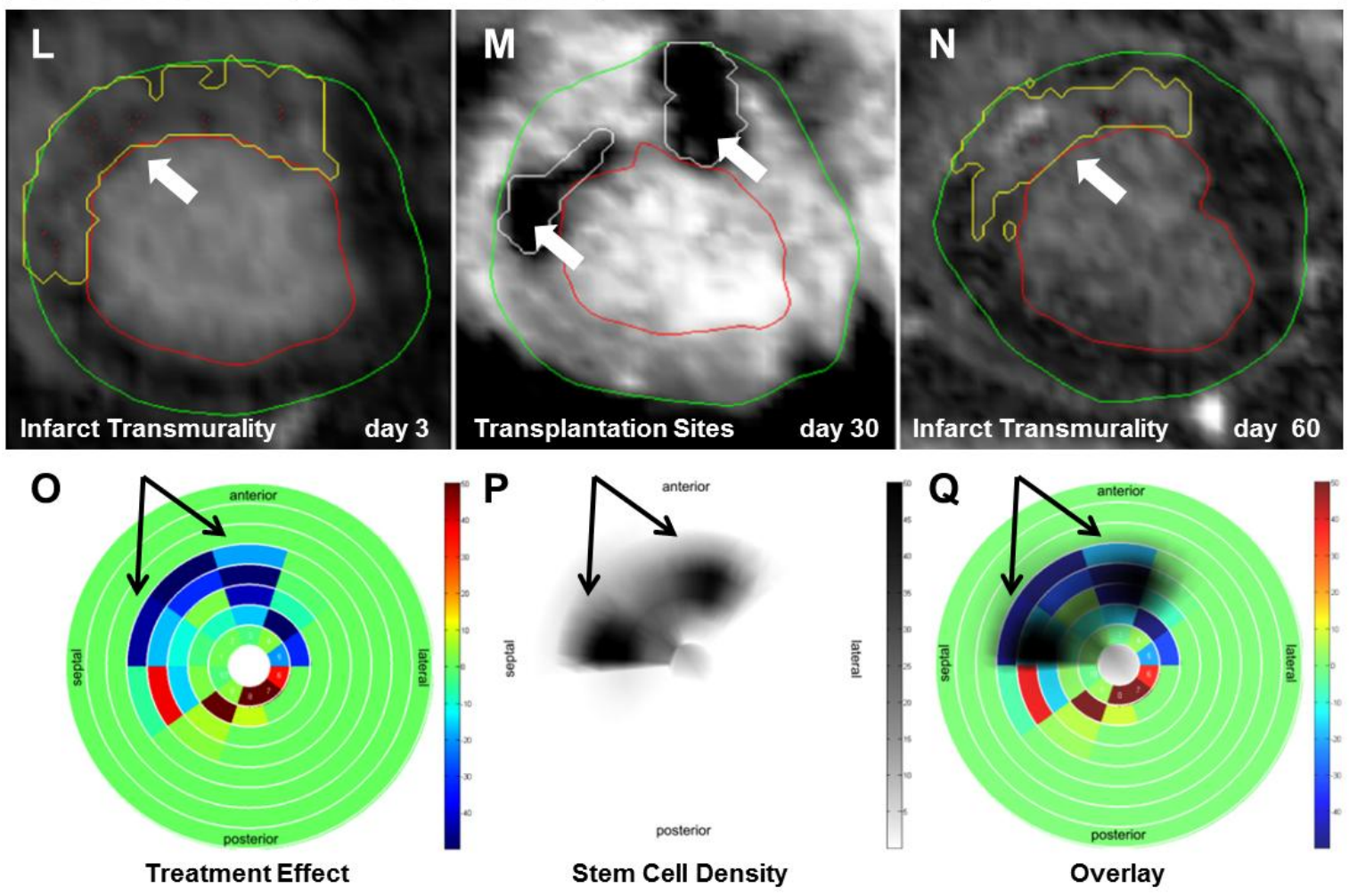
Figure 6:
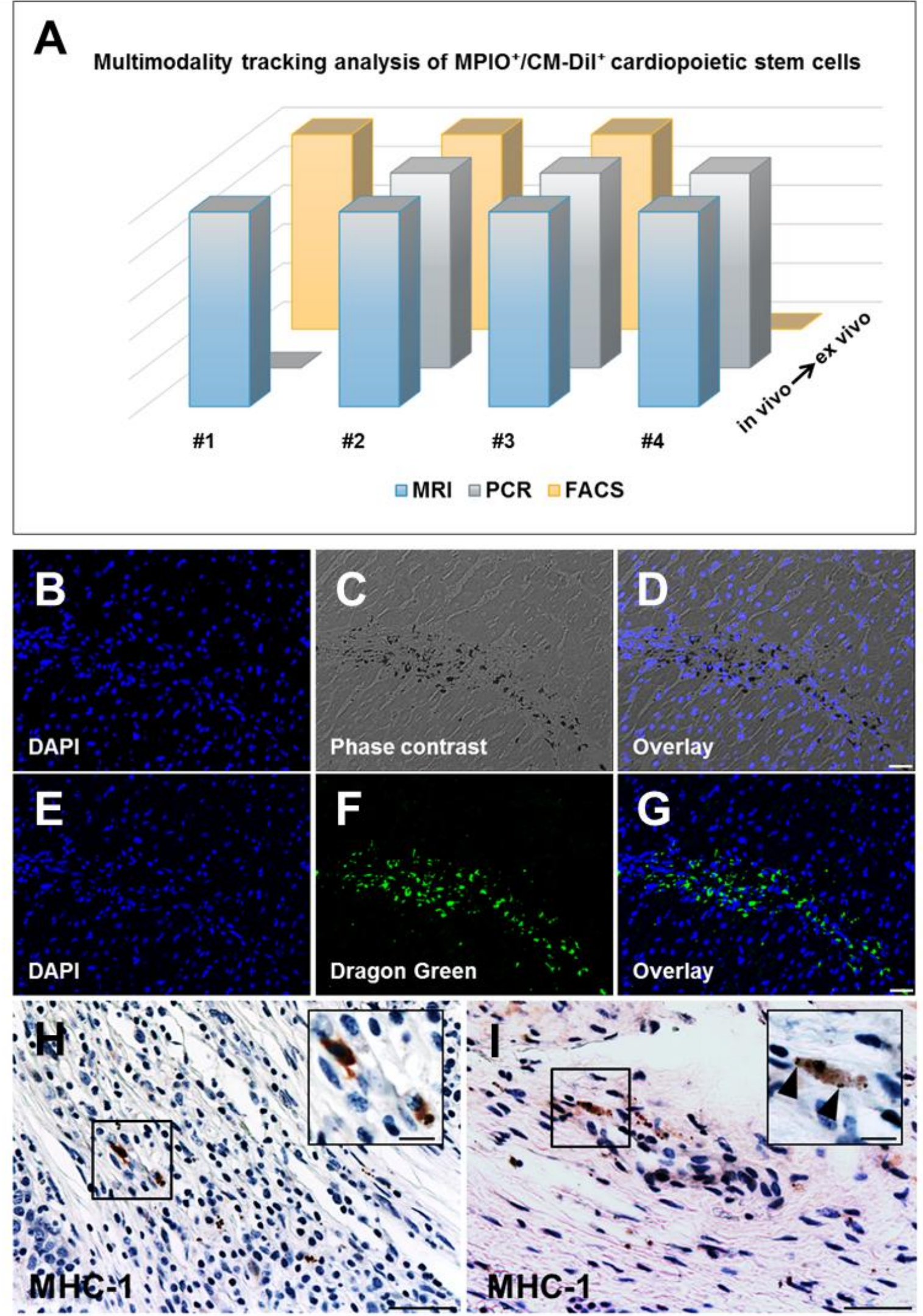
Figure 7:

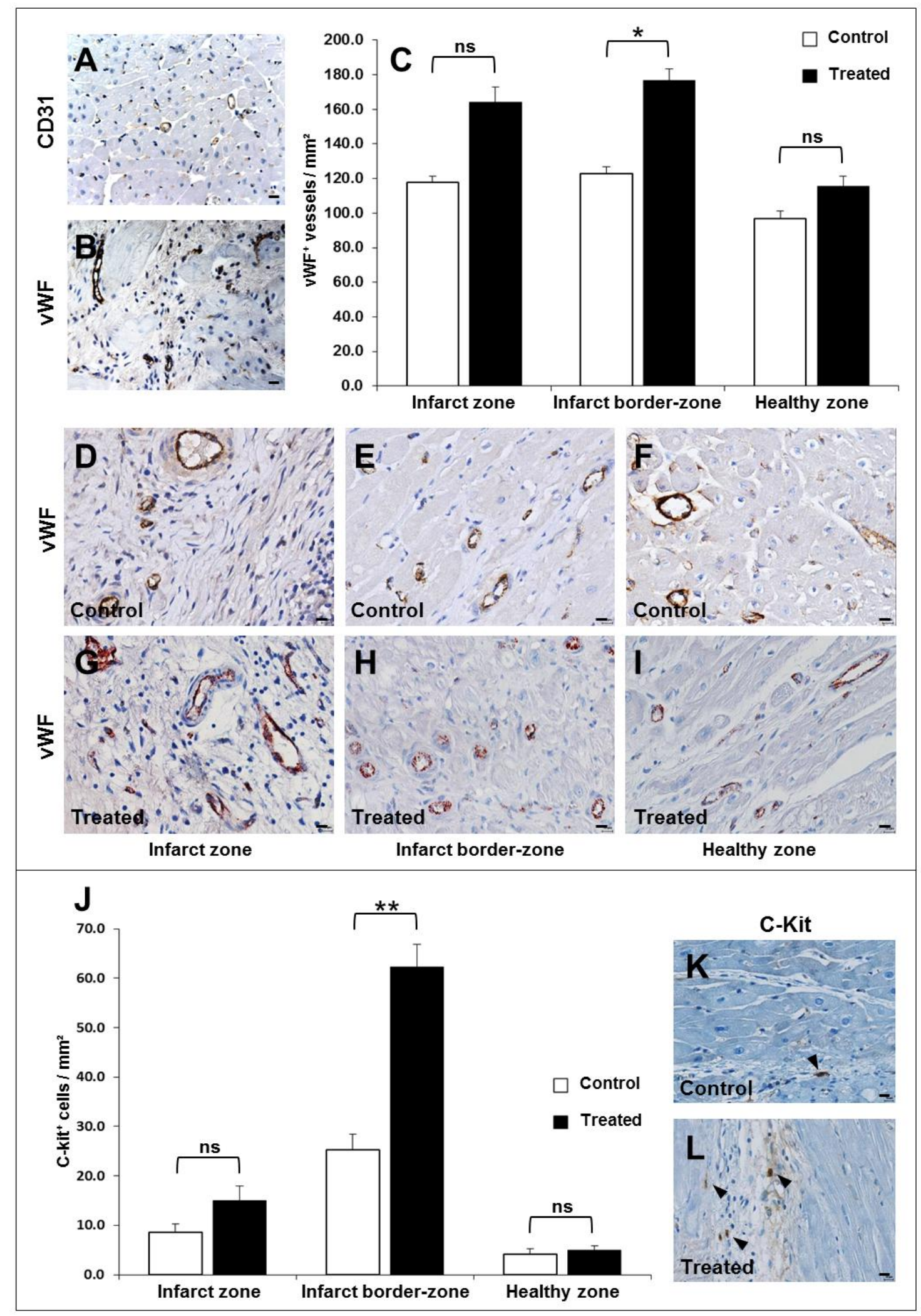


Figure 8:
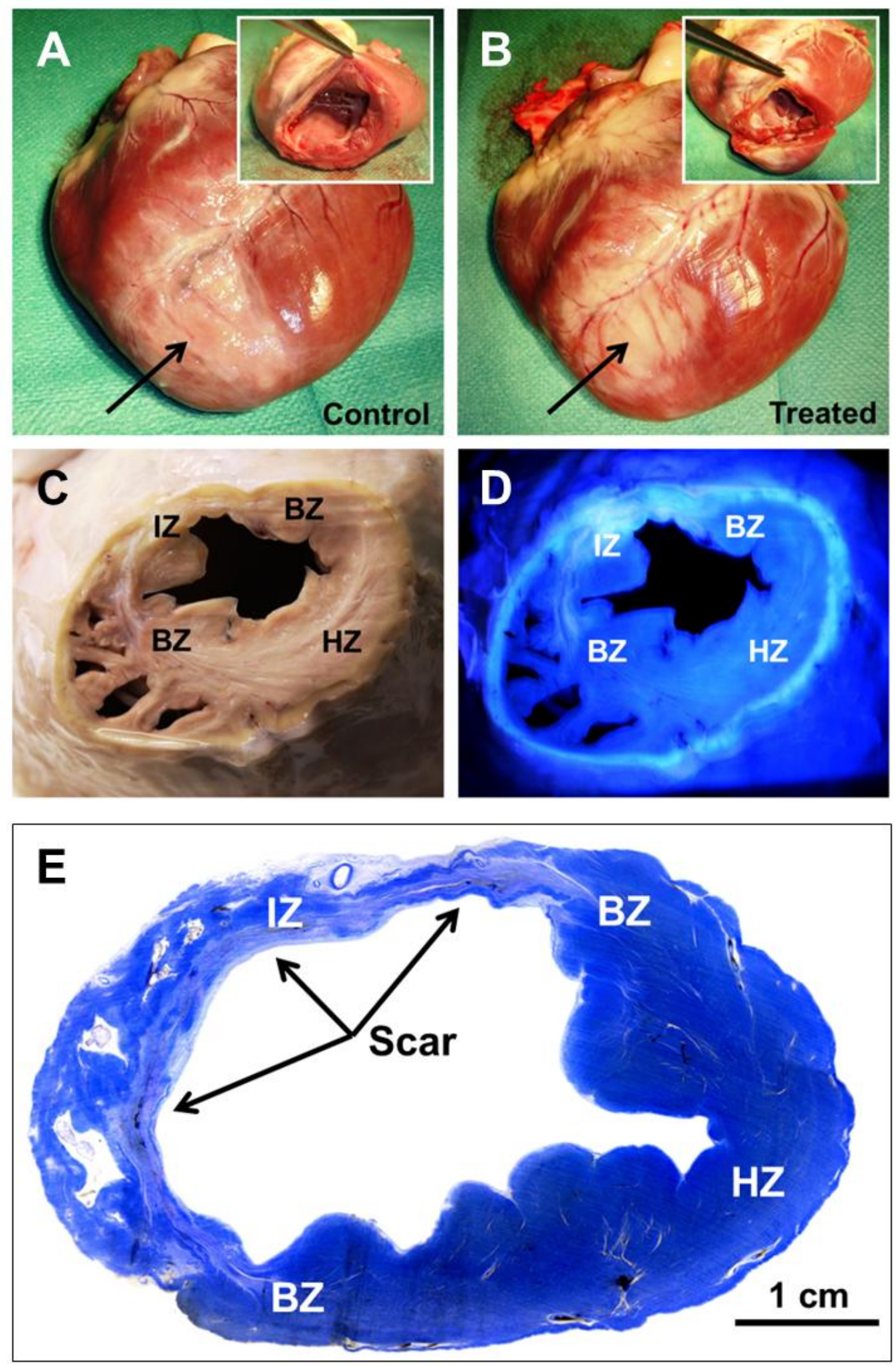